\title{
Impaired Chronotropic Response to Exercise in Acute Myocardial Infarction Patients with Type 2 Diabetes Mellitus
}

\author{
Kazuhiro IzAwA, ${ }^{1}$ RPT, Kazuhiko TANABE, ${ }^{2} \mathrm{MD}$, Kazuto OMIYA, ${ }^{2} \mathrm{MD}$, \\ Sumio YAMADA, ${ }^{1} \mathrm{RPT}, \mathrm{PhD}$, Yasuhiro YOKOYAMA, ${ }^{2} \mathrm{MD}$, \\ Tomoyasu Ishiguro, ${ }^{1}$ RPT, Maiko YAGI, ${ }^{1}$ RPT, Yasuyuki HIRANO,${ }^{1}$ RPT, \\ Yusuke KASAHARA, ${ }^{1}$ RPT, Naohiko OSADA, ${ }^{2}$ MD, Fumihiko MIYAKE, ${ }^{2}$ MD, \\ and Masahiro MURAYAMA, ${ }^{2} \mathrm{MD}$
}

\section{SUMMARY}

This study was undertaken in acute myocardial infarction (AMI) patients with noninsulin-dependent diabetes mellitus (type $2 \mathrm{DM}$ ) to investigate their impaired chronotropic response to exercise. Seventy-one AMI subjects entered the study, 30 with type 2 DM and 41 age- and body mass index-matched non-DM (control) patients. One month after the onset of AMI, these patients underwent cardiopulmonary exercise testing on a treadmill under a ramp protocol. Anaerobic threshold (AT) and peak oxygen uptake (peak $\dot{\mathrm{V}} \mathrm{O}_{2}$ ) were determined as indicators of exercise capacity. Plasma norepinephrine (NE) concentration was measured in blood samples obtained at 2 time points: during pre-exercise rest and immediately after peak exercise. The change in NE concentration during exercise, as an index of sympathetic nervous activity, was calculated as a percentage: $\Delta \mathrm{NE}=[(\mathrm{NE}$ during exercise $)$-(resting value $)] /($ resting value $) \times 100$. The change in heart rate $(\mathrm{HR})$ during exercise was calculated as a simple difference: $\Delta \mathrm{HR}=[($ peak HR) - (rest $\mathrm{HR})]$. Index of chronotropic response to exercise was then quantified as the $\Delta \mathrm{HR} / \Delta \mathrm{NE}$ during exercise. No significant intergroup differences in ejection fraction at rest or HR at peak exercise were observed. However, $\dot{\mathrm{V}}_{2}$ at AT, peak $\dot{\mathrm{V}}_{2}, \Delta \mathrm{HR}$, and $\Delta \mathrm{HR} / \Delta \mathrm{NE}$ were significantly lower in the type $2 \mathrm{DM}$ group than in the non-DM group. $\Delta \mathrm{HR}$ correlated with $\dot{\mathrm{V}} \mathrm{O}_{2}$ at AT $(r=0.49, P<0.001)$ and with peak $\dot{\mathrm{V}} \mathrm{O}_{2}(r=0.53, P<0.001)$ in all subjects. Also, $\Delta \mathrm{HR} / \Delta \mathrm{NE}$ correlated with $\dot{\mathrm{V}} \mathrm{O}_{2}$ at $\mathrm{AT}(r=0.42, P<0.001)$ and with peak $\dot{\mathrm{VO}}{ }_{2}$ $(r=0.44, P<0.001)$ in all subjects. AMI patients with type 2 DM had impaired cardiopulmonary responses to maximal and submaximal exercise testing and impaired chronotropic response to exercise, even though their cardiac function at rest was similar to that of non-DM AMI patients. The data suggest that one mechanism of impaired cardiopulmo-

From ${ }^{1}$ Department of Rehabilitation Medicine, ${ }^{2}$ Division of Cardiology, Department of Internal Medicine, St. Marianna University School of Medicine, Kawasaki, Japan.

Address for correspondence: Kazuhiro Izawa, RPT, Department of Rehabilitation Medicine, St. Marianna University School of Medicine Hospital, 2-16-1 Sugao, Miyamae-ku, Kawasaki, Kanagawa 216-8511, Japan.

Received for publication April 16, 2002.

Revised and accepted August 16, 2002. 
nary response to exercise in AMI patients with type 2 DM groups is an impaired chronotropic response. (Jpn Heart J 2003; 44: 187-199)

Key words: Diabetes mellitus, Myocardial infarction, Exercise capacity, Chronotropic response

Non-INSULIN-DEPENDENT diabetes mellitus (type 2 DM) is associated with increased morbidity and mortality due to atherosclerotic and microvascular diseases. ${ }^{1)}$ Acute myocardial infarction (AMI) in patients with diabetes carries with it a high risk of mortality. ${ }^{2-3)}$ Although the prevalence of diabetes is estimated to be lower in Japan than in Western countries, ${ }^{4}$ epidemiological surveys have shown that diabetes among Japanese has been increasing quite rapidly in recent years. ${ }^{4}$ This is probably due to increased fat intake in the Japanese diet and a lack of exercise, a conception supported by a concomitant increase in the prevalence of obesity and hyperlipidemia in Japan..$^{5-6)}$ In persons with diabetes, there are several pathological factors that can be involved in decreased exercise capacity. Regensteiner, et $a l^{7)}$ observed that both male and female type 2 DM patients, in the absence of known complications, have reduced exercise capacity compared with age- and activity-matched normal subjects. Other researchers have reported that reduced cardiac output during exercise is found in patients with type $2 \mathrm{DM}^{8}{ }^{8}$ Less well understood are the abnormal cardiovascular responses to exercise that are caused by cardiac autonomic nervous system dysfunction in type 2 DM patients. $^{8-9)}$

In a previous study, patients with type $2 \mathrm{DM}$ who had had an AMI showed impaired cardiopulmonary responses to maximal and submaximal exercise testing, even when their cardiac function at rest was similar to that of non-diabetes mellitus (DM) patients with AMI. ${ }^{10)}$ The mechanism for this difference was not clarified. It has been suggested that impaired myocardial function and impaired oxygen transport in persons with type 2 DM may play a critical role in the abnormal exercise performance observed in these individuals. ${ }^{7)}$

In patients with congestive heart failure (CHF), the chronotropic response to peak exercise is reduced, and this reduction may play some part in the impaired cardiac output response during exercise. ${ }^{11)}$

Another previous report suggested that the ratio between the incremental changes in heart rate (HR) and norepinephrine (NE) concentrations during exercise, an indirect index of sino-atrial node sympathetic responsiveness, is markedly reduced in CHF patients and that this ratio inversely correlates with the severity of exercise impairment. ${ }^{12}$

We hypothesized that patients with type $2 \mathrm{DM}$ who have had an AMI would 
have reproducible impairment in peak exercise performance in comparison to that of age-matched non-DM AMI patients, and we investigated whether such impairment is associated with a chronotropic response. Therefore, in this study, we investigated the chronotropic response via assessment of $\mathrm{NE}$ concentration changes as an index of sympathetic nervous activity.

\section{SUBJECTS AND METHODS}

The study subjects were selected from among 49 consecutive DM patients who were admitted to St. Marianna University School of Medicine Hospital for evaluation of AMI between November 1998 and March 2000. The study subjects were scheduled for cardiopulmonary exercise testing at 1 month after the onset of AMI. The diagnosis of AMI was made on the basis of chest pain persisting for at least 30 minutes, ST-segment elevation of at least $0.1 \mathrm{mV}$ in at least 2 contiguous leads, and serum creatine kinase-myocardial band (CK-MB) elevation to more than twice the upper limit of normal. Patients were considered to have type $2 \mathrm{DM}$ if they were already receiving oral hypoglycemic therapy or dietary treatment for type $2 \mathrm{DM}$ or if, after admission, an oral glucose tolerance test was positive for the disease according to the World Health Organization criteria. Patients with type 2 DM that was controlled with insulin were included in this study. ${ }^{13-14)}$

Of the 49 type 2 DM patients, 30 who completed the exercise testing and a routine 4-week AMI cardiac rehabilitation program were included in this study. The remaining 19 patients failed to complete the test because of cerebrovascular disease, an orthopedic disorder, ST segment changes, or chest pain during exercise and were therefore excluded from the study. The patients with type $2 \mathrm{DM}$ had been first diagnosed with the disease an average of $8.54 \pm 8.24$ years earlier. Forty-one non-DM patients with AMI who matched the 30 study patients with respect to age, height, and CK-MB level and who had completed the same exercise test during the same period were selected retrospectively as control subjects from among 71 potential control subjects.

All 71 subjects completed the routine 4-week AMI cardiac rehabilitation program while hospitalized. Patients with severe heart failure, angina pectoris, ischemic ST segment changes, uncontrolled arrhythmia, atrial fibrillation, valvular heart disease, treatment with beta-blockers, or left bundle branch block were excluded. Those having had coronary artery bypass surgery or who were above 75 years of age were also excluded. Prescribed cardiac medications were continued on the day of the exercise test.

Ethical considerations: The study was approved by the St. Marianna University School of Medicine institutional committee on human research. Informed consent was obtained from each patient at 1 month after the onset of AMI. 
Study protocol: Subjects underwent cardiopulmonary exercise testing under a ramp treadmill protocol ${ }^{15)} 1$ month after the onset of AMI. Anaerobic threshold (AT), peak oxygen uptake $\left(\dot{\mathrm{V}}_{2}\right)$, and peak exercise time were measured. Expired gas analysis was used as an index of cardiovascular dynamics during exercise.

Exercise test: Symptom-limited exercise testing was undertaken with a MAT2500 treadmill (Fukuda Denshi Co., Tokyo). Patients rested for 3 minutes on the treadmill. Exercise began with a 3-minute warm-up (speed, $1.0 \mathrm{mph}$; grade, $0 \%$ ) which was followed by an increase (speed or grade) in the load every 60 seconds. Throughout the test, a 12-lead electrocardiogram (ECG) was continuously monitored, and heart rate (HR) was measured from the R-R interval of the ECG (ML5000, Fukuda Denshi Co.,). Systolic blood pressure was measured by the cuff method via an automatic blood pressure monitor (stress test system, STBP-780, Colin Co., Aichi, Japan) at 1-minute intervals. $\dot{\mathrm{V}} \mathrm{O}_{2}$, carbon dioxide production $\left(\dot{\mathrm{V} C O}{ }_{2}\right)$, minute ventilation $(\dot{\mathrm{V} E})$, tidal volume $(\mathrm{TV})$, end tidal $\mathrm{CO}_{2}\left(\mathrm{ETCO}_{2}\right)$, and the ventilatory equivalent for $\mathrm{CO}_{2}\left(\dot{\mathrm{VE}} / \dot{\mathrm{V}} \mathrm{CO}_{2}\right)$ were measured throughout the exercise period with an RM-300 respiromonitor and a MG-360 gas analyzer (Minato Ikagaku Co., Tokyo). The measurement system for cardiopulmonary exercise testing was carefully calibrated before the start of each individual test. Expired gas was sampled using a breath-by-breath method. The endpoint of exercise testing was determined. ${ }^{16)}$ The appearance of a leveling-off of $\dot{\mathrm{V}} \mathrm{O}_{2}\left(\dot{\mathrm{V}} \mathrm{O}_{2}\right.$ plateau despite increasing exercise intensity) assisted in determination of the exercise endpoint.

Parameters evaluated: Ventilatory equivalents were calculated for $\mathrm{O}_{2}$ ( $\dot{\mathrm{V} E} /$ $\left.\dot{\mathrm{V}} \mathrm{O}_{2}\right)$, and $\mathrm{CO}_{2}\left(\dot{\mathrm{VE}} / \dot{\mathrm{V}} \mathrm{CO}_{2}\right)$, and the gas exchange ratio (GER) $\left(\dot{\mathrm{V}} \mathrm{CO}_{2} / \dot{\mathrm{V}} \mathrm{O}_{2}\right)$ on a personal computer (Model PC-9801, NEC Co., Tokyo). AT was determined by the original $\mathrm{V}$-slope method ${ }^{17)}$ as well as conventionally by determining when $\dot{\mathrm{VE}} / \dot{\mathrm{V}} \mathrm{O}_{2}$ increases after holding constant or decreases while $\dot{\mathrm{V}} / \dot{\mathrm{V}} \mathrm{CO}_{2}$ remains constant or decreases, and by determining the period at which GER starts to increase steeply. ${ }^{18)}$

Cardiac catheterization: At 1 month after the onset of AMI, left ventriculography and selective coronary angiography were performed in all subjects according to the Judkins technique. Ejection fraction was calculated via biplane left ventriculography. The luminal diameter of the coronary artery was measured by comparing the average diameter loss with the nearest proximal normal segment.

Blood sampling: Blood samples for measurement of NE were obtained from a catheter inserted into an antecubital vein at 2 time points: during pre-exercise resting and immediately after peak exercise. The sampled blood was immediately ice-cooled and centrifuged for 10 minutes at $4^{\circ} \mathrm{C}$ and $3000 \mathrm{rpm}$, thereby separating the plasma, which was maintained in frozen storage at $-70^{\circ} \mathrm{C}$ until the day of analysis. NE was extracted by absorption on an activated alumina microcolumn 
and then quantitated by high pressure liquid chromatography. The change in NE concentration during exercise was calculated as a percentage: $\Delta \mathrm{NE}=[(\mathrm{NE}$ during exercise) - (resting value) $] /($ resting value $) \times 100$.

Sympathetic nervous activity: Sympathetic nervous activity was then quantified as a ratio representing the relation between $\mathrm{HR}$ and NE during exercise. The change in HR during exercise was calculated as: $\Delta \mathrm{HR}=[($ peak HR) - (rest HR)]. The change in the HR to NE ratio during exercise was calculated as: $\Delta \mathrm{HR} /$ $\Delta \mathrm{NE} \times 10^{2}$.

Statistical analysis: All data are expressed as the mean \pm SD. The patient characteristics and results were compared using an unpaired $t$-test for parametric factors and $\chi^{2}$ test for nonparametric factors. Regression analysis (least-squares linear estimation) was used to determine the correlations between $\Delta \mathrm{HR}$ and $\dot{\mathrm{VO}} \mathrm{O}_{2}$ at AT, peak $\dot{\mathrm{V}} \mathrm{O}_{2}$, and between $\Delta \mathrm{HR} / \Delta \mathrm{NE}$ and $\dot{\mathrm{VO}}_{2}$ at $\mathrm{AT}$, peak $\dot{\mathrm{VO}}_{2}$. Statistical analyses were performed with an SPSS 9.0J statistical software program (SPSS Japan, Inc.), and a $P$ value of $<0.05$ was considered significant.

\section{Results}

Clinical characteristics of the two groups: We evaluated several patient characteristics, including age, height, weight, treatment in the acute phase of AMI, number of diseased coronary arterial vessels, CK-MB, and dosages of medications (Table I). The mean age, height, weight, and body mass index (BMI) of the subjects were almost identical between the two groups. During the acute phase of AMI, direct percutaneous transluminal coronary angioplasty (PTCA) was performed in 61 patients, and intracoronary thrombolysis (ICT) was performed in 10. Other patients were treated conservatively during the acute phase of AMI. The oral dosages of drugs did not differ statistically between the two groups. The ejection fraction 1 month after the onset of AMI did not differ significantly in the type 2 DM group $(47.7 \pm 10.2 \%)$ and the non-DM group $(48.6 \pm 8.3 \%)$. The difference between left ventricular end-diastolic volume index between the groups 1 month after onset of AMI was also insignificant: $81.9 \pm 20.7 \mathrm{~mL} / \mathrm{m}^{2}$ in the type 2 $\mathrm{DM}$ group and $82.6 \pm 19.8 \mathrm{~mL} / \mathrm{m}^{2}$ in the non-DM group.

The percentages of patients treated with various drugs did not differ significantly between the two groups. Before PTCA or ICT, triple-vessel coronary artery stenosis was found significantly more often $(P<0.05)$ in the DM patients than in the non-DM patients, whereas single-vessel disease was found significantly more often in the non-DM patients than in the DM patients $(P<0.05)$. After PTCA or ICT, all differences between the groups were insignificant.

Exercise tolerance and HR response during exercise: The endpoint of the exercise test for both groups was leg fatigue, shortness of breath, and GER $\geq 1.20$. No 
Table I. Clinical Factors in the Two Study Groups

\begin{tabular}{|c|c|c|}
\hline & AMI with DM $(n=30)$ & AMI without DM $(n=41)$ \\
\hline Age (years) & $58.1 \pm 8.4$ & $57.5 \pm 8.7$ \\
\hline Height $(\mathrm{cm})$ & $164.7 \pm 6.1$ & $163.3 \pm 7.2$ \\
\hline Weight $(\mathrm{kg})$ & $59.8 \pm 7.6$ & $61.5 \pm 8.3$ \\
\hline BMI $\left(\mathrm{kg} / \mathrm{m}^{2}\right)$ & $22.3 \pm 2.4$ & $23.2 \pm 2.6$ \\
\hline HgAlc $(\%)$ & $6.9 \pm 1.5$ & \\
\hline Maximum CK-MB (TU/I) & $202.4 \pm 191.8$ & $258.2 \pm 182.1$ \\
\hline LVEF (\%) & $47.7 \pm 10.2$ & $48.6 \pm 8.3$ \\
\hline $\operatorname{LVEDVI}\left(\mathrm{mL} / \mathrm{m}^{2}\right)$ & $81.9 \pm 20.7$ & $82.6 \pm 19.8$ \\
\hline \multicolumn{3}{|l|}{ Location of MI } \\
\hline Anterior & $13(43 \%)$ & $18(44 \%)$ \\
\hline Inferior & $14(46 \%)$ & $18(44 \%)$ \\
\hline Lateral & $3(10 \%)$ & $5(12 \%)$ \\
\hline \multicolumn{3}{|l|}{ Medications used during study } \\
\hline Nitrates & $19(63 \%)$ & $22(54 \%)$ \\
\hline $\mathrm{Ca}$ antagonist & $7(23 \%)$ & $10(24 \%)$ \\
\hline ACE inhibitors & $17(56 \%)$ & $27(66 \%)$ \\
\hline OHA & $18(60 \%)$ & \\
\hline Insulin & $1(3 \%)$ & \\
\hline Diet & $11(36 \%)$ & \\
\hline \multicolumn{3}{|c|}{$\begin{array}{l}\text { Signilicant stenosis }(\geq 75 \%) \text { of } \\
\text { coronary arteries before PTCA or ICT }\end{array}$} \\
\hline OVD & $1(3 \%)$ & $1(2 \%)^{*}$ \\
\hline $1 \mathrm{VD}$ & $13(43 \%)$ & $26(64 \%)$ \\
\hline $2 \mathrm{VD}$ & $12(40 \%)$ & $13(32 \%)$ \\
\hline $3 \mathrm{VD}$ & $4(13 \%)$ & $1(2 \%)$ \\
\hline \multicolumn{3}{|l|}{ After PTCAor ICT } \\
\hline 0VD & $15(50 \%)$ & $22(54 \%)$ \\
\hline $1 \mathrm{VD}$ & $10(33 \%)$ & $13(32 \%)$ \\
\hline $2 \mathrm{VD}$ & $5(16 \%)$ & $6(15 \%)$ \\
\hline $3 \mathrm{VD}$ & $0(0 \%)$ & $0(0 \%)$ \\
\hline \multicolumn{3}{|c|}{$\begin{array}{l}\mathrm{DM}=\text { diabetes mellitus; } \mathrm{BMI}=\text { body mass index; } \mathrm{CK}-\mathrm{MB}=\text { creatine kinase-MB; } \\
\mathrm{LVEF}=\text { left ventricular ejection fraction, } \mathrm{LVEDVI}=\text { left ventricular end-diastolic volume } \\
\text { index; } \mathrm{ACE}=\text { angiotensin converting enzyme inhibitors; OHA = oral hypoglycemic agent; } \\
\mathrm{VD}=\text { vessel disease; } \mathrm{MI}=\text { myocardial infarction; PTCA = percutaneous transluminal coro- } \\
\text { nary angioplasty; ICT = intracoronary thrombolysis; LVEF was measured in } 30 \text { patients } \\
\text { with DM and in } 40 \text { patients with non-DM. }{ }^{*} P<0.05 \text {. }\end{array}$} \\
\hline
\end{tabular}

patient showed ischemic ST changes or experienced chest pain during exercise testing. The change in $\dot{\mathrm{VO}}_{2}$ at $\mathrm{AT}$ and at the peak exercise differed between the two groups: $\dot{\mathrm{V}} \mathrm{O}_{2}$ at $\mathrm{AT}$ was significantly lower in the type $2 \mathrm{DM}$ group than in the non-DM group $\left(14.6 \pm 2.7\right.$ vs $16.8 \pm 2.1 \mathrm{~mL} / \mathrm{min} / \mathrm{kg}, P<0.01$, Table II). $\dot{\mathrm{VO}}_{2}$ at peak exercise was also significantly lower in the DM group than in the non-DM group (22.6 \pm 4.5 vs $26.1 \pm 3.4 \mathrm{~mL} / \mathrm{min} / \mathrm{kg}, P<0.01)$. HR at rest tended to be 
Table II. Cardiopulmonary Exercise Testing Results

\begin{tabular}{lcc}
\hline & AMI with DM $(n=30)$ & AMI without DM $(n=41)$ \\
\hline Peak values & $1373.2 \pm 327.9$ & $1644.2 \pm 357.3^{*}$ \\
$\mathrm{VO}_{2}, \mathrm{~mL} / \mathrm{min}$ & $22.6 \pm 4.5$ & $26.1 \pm 3.4^{*}$ \\
$\mathrm{VO}_{2}, \mathrm{~mL} / \mathrm{min} / \mathrm{kg}$ & $135.6 \pm 16.7$ & $143.0 \pm 16.2$ \\
$\mathrm{HR}$, beats/min & $172.4 \pm 29.5$ & $170.4 \pm 23.7$ \\
$\mathrm{SBP}, \mathrm{mmHg}$ & $1761.3 \pm 929.5$ & $1769.5 \pm 1005.2$ \\
$\mathrm{NE}, \mathrm{pg} / \mathrm{mL}$ & & \\
$\mathrm{AT}$ values & $894.8 \pm 192.3$ & $1045.8 \pm 193.5^{*}$ \\
$\mathrm{VO}, \mathrm{mL} / \mathrm{min}$ & $14.6 \pm 2.7$ & $16.8 \pm 2.1^{*}$ \\
$\mathrm{VO}, \mathrm{mL} / \mathrm{min} / \mathrm{kg}$ & $104.0 \pm 12.5$ & $104.3 \pm 14.2$ \\
$\mathrm{HR}, \mathrm{beats} / \mathrm{min}$ & $143.4 \pm 18.3$ & $142.3 \pm 20.1$ \\
$\mathrm{SBP}, \mathrm{mmHg}$ & & \\
$\mathrm{Rest} \mathrm{values}$ & & \\
$\mathrm{VO}, \mathrm{mL} / \mathrm{min}$ & $253.3 \pm 35.8$ & $252.0 \pm 42.0$ \\
$\mathrm{VO}, \mathrm{mL} / \mathrm{min} / \mathrm{kg}$ & $4.2 \pm 0.5$ & $4.0 \pm 0.4$ \\
$\mathrm{HR}, \mathrm{beats} / \mathrm{min}$ & $75.3 \pm 13.2$ & $70.9 \pm 11.1$ \\
$\mathrm{SBP}, \mathrm{mmHg}$ & $122.5 \pm 13.3$ & $114.5 \pm 14.5$ \\
$\mathrm{NE}, \mathrm{pg} / \mathrm{mL}$ & $242.7 \pm 137.1$ & $254.6 \pm 150.4$ \\
\hline
\end{tabular}

Values are expressed as mean $\pm \mathrm{SD}$. $\mathrm{DM}=$ diabetes mellitus; $\mathrm{AT}=$ anaerobic threshold; $\mathrm{VO}_{2}=$ oxygen uptake; $\mathrm{HR}=$ heart rate; $\mathrm{SBP}=$ systolic blood pressure, $\mathrm{NE}=$ norepinephrine; ${ }^{*} P<0.05$.

higher in the DM group than in the non-DM group, but the difference was not significant $(75.3 \pm 13.2$ vs $70.9 \pm 11.1$ beats $/ \mathrm{min}, \mathrm{NS})$. HR at peak did not differ significantly between the type $2 \mathrm{DM}$ group and the non-DM group (135.6 $\pm 16.7 \mathrm{vs}$ $143.0 \pm 16.2$ beats $/ \mathrm{min}, \mathrm{NS})$. Intergroup differences in systolic blood pressure at rest and during exercise were insignificant.

$\triangle \mathrm{HR}$ was significantly lower in the DM group than in the non-DM group ( $58.5 \pm 14.1$ vs $73.5 \pm 13.7$ beats, $P<0.01$, Figure 1 ). $\Delta \mathrm{HR} / \Delta \mathrm{NE}$ was also significantly lower in the DM group than in the non-DM group (10.2 \pm 4.9 vs $13.1 \pm 4.2$ beats $/ \%, P<0.01$, Figure 2). When the values of $\Delta \mathrm{HR}$ in relation to $\dot{\mathrm{VO}}_{2}$ at $\mathrm{AT}$ and to peak $\dot{\mathrm{VO}}_{2}$ for all subjects were plotted (Figure 3), significant positive correlations between $\Delta \mathrm{HR}$ and AT $(r=0.49, P<0.001)$ and peak $\dot{\mathrm{V}} \mathrm{O}_{2}(r=0.53$, $P<0.001)$ were observed. When the values of $\Delta \mathrm{HR} / \Delta \mathrm{NE}$ in relation to $\dot{\mathrm{V}} \mathrm{O}_{2}$ at AT and to peak $\dot{\mathrm{VO}}_{2}$ for all subjects were plotted (Figure 4), significant positive correlations between $\Delta \mathrm{HR} / \Delta \mathrm{NE}$ and AT $(r=0.42, P<0.001)$ and peak $\dot{\mathrm{V}} \mathrm{O}_{2}$ $(r=0.44, P<0.001)$ were also observed. 


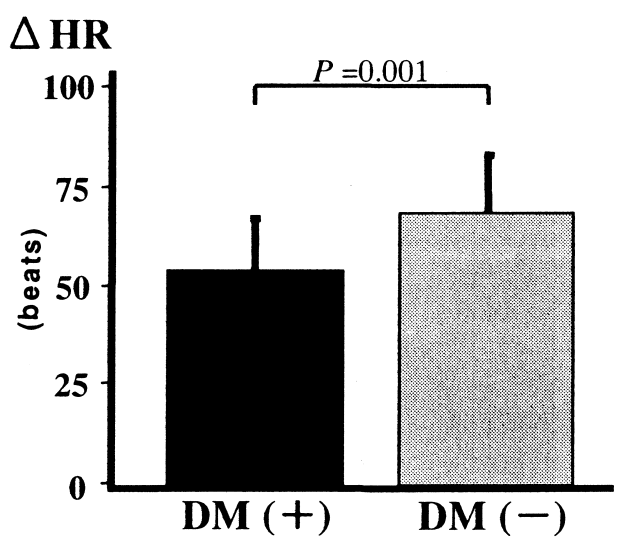

Figure 1. $\Delta \mathrm{HR}$ values (mean $\pm \mathrm{SD}$ ) 1 month after the onset of AMI. $\Delta \mathrm{HR}$ was significantly lower in the type $2 \mathrm{DM}$ group than in the non-DM group. AMI = acute myocardial infarction; $\mathrm{HR}=$ heart rate.

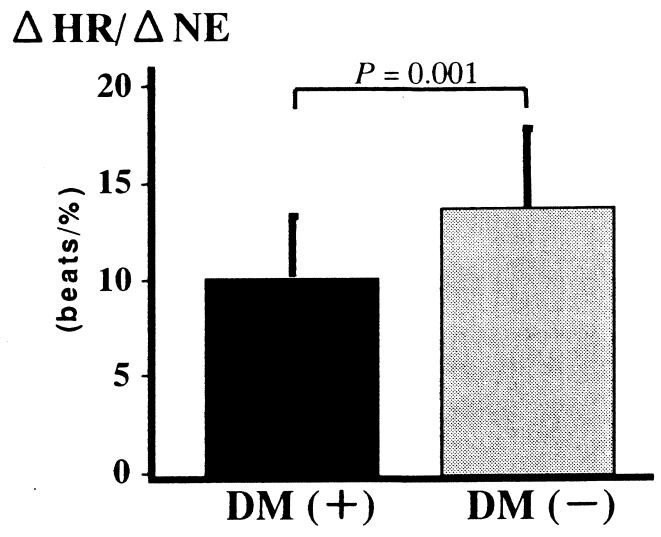

Figure 2. $\Delta \mathrm{HR} / \Delta \mathrm{NE}$ values (mean $\pm \mathrm{SD}$ ) 1 month after the onset of AMI. $\Delta \mathrm{HR} / \Delta \mathrm{NE}$ was significantly lower in the type $2 \mathrm{DM}$ group than in the non-DM group. $\mathrm{AMI}=$ acute myocardial infarction; $\mathrm{HR}=$ heart rate; $\mathrm{NE}=$ norepinephrine.

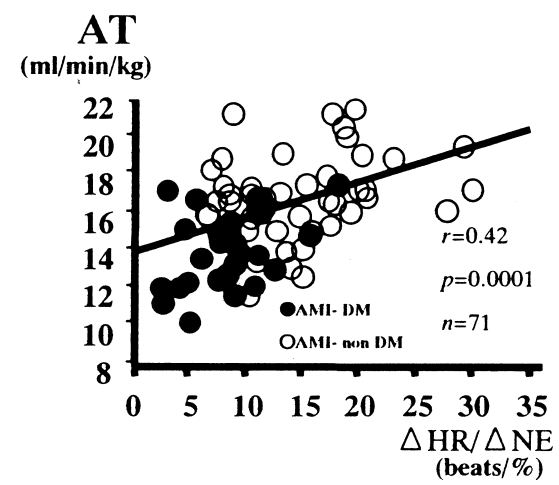

$\underset{(\mathbf{m l} / \mathbf{m i n} / \mathbf{k g})}{\text { Peak }}$

Figure 3. Correlations between $\Delta \mathrm{HR}$ and $\mathrm{VO}_{2}$ at $\mathrm{AT}$ and $\Delta \mathrm{HR}$ and peak $\mathrm{VO}_{2}$ in all patients combined. A positive correlation was observed between $\Delta \mathrm{HR}$ and $\mathrm{VO}_{2}$ at $\mathrm{AT}$, and at peak $\mathrm{VO}_{2} . \mathrm{VO}_{2}=$ oxygen uptake; $\mathrm{HR}=$ heart rate; $\mathrm{NE}=$ norepinephrine; $\mathrm{AT}=$ anaerobic threshold. 

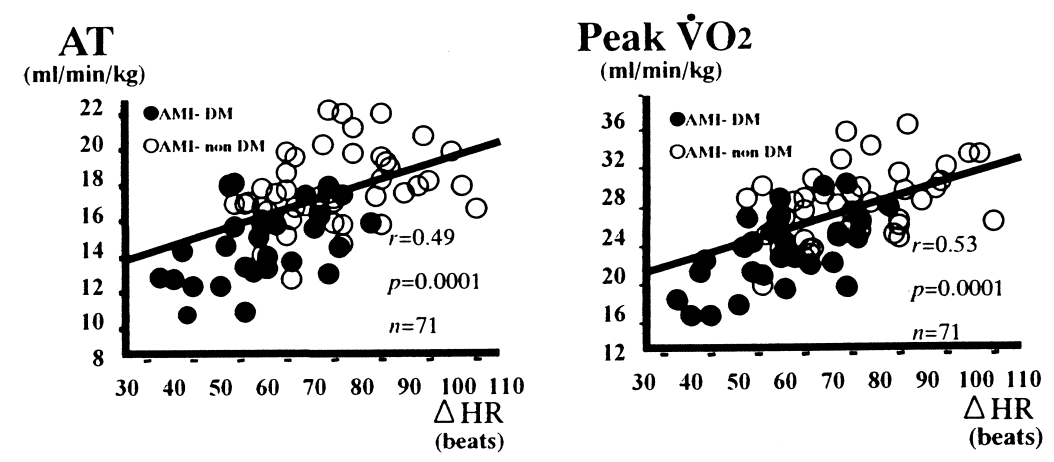

Figure 4. Correlations between $\Delta \mathrm{HR} / \Delta \mathrm{NE}$ and $\mathrm{VO}_{2}$ at $\mathrm{AT}$ and $\Delta \mathrm{HR} / \Delta \mathrm{NE}$ and peak $\mathrm{VO}_{2}$ in all patients combined. A positive correlation was observed between $\Delta \mathrm{HR} / \Delta \mathrm{NE}$ and $\mathrm{VO}_{2}$ at $\mathrm{AT}$, and at peak $\mathrm{VO}_{2} . \mathrm{VO}_{2}=$ oxygen uptake; $\mathrm{HR}=$ heart rate; $\mathrm{NE}=$ norepinephrine; $\mathrm{AT}=$ anaerobic threshold.

\section{DISCUSSION}

Since the number of AMI patients with DM has increased remarkably in Japan over the past decade, ${ }^{5)}$ we undertook an exercise physiology study to determine an appropriate cardiac rehabilitation protocol for such patients. The immediate goal of the study was to examine the relationship between the autonomic nervous system and HR responses during exercise in AMI patients with type 2 DM. We found that peak $\dot{\mathrm{V}} \mathrm{O}_{2}$ and AT in patients with type 2 DM were lower than those of non-DM patients, even though they had similar indices of cardiac function during the resting state (Table II). There are potential causes for the reduced exercise capacity among diabetics with sensorineural and autonomic dysfunction. ${ }^{19)}$ In the present study, $\Delta$ HR were significantly lower in our type 2 DM group than in our non-DM group. Also, when both groups were considered together, we found a significant positive correlation between $\Delta \mathrm{HR}$ and AT and between $\Delta \mathrm{HR}$ and peak $\dot{\mathrm{VO}}_{2}$. Impaired HR response to exercise has been regarded as chronotropic incompetence. ${ }^{20)}$ Chronotropic incompetence, defined as an inadequate HR increase to a given level of exercise, has been considered as a marker for the presence of coronary artery disease. ${ }^{21)}$ It seems likely that an impaired HR response is closely related to the impaired cardiac performance even in the type $2 \mathrm{DM}$ patients.

Diabetes mellitus may be associated with the development of 1) macroscopic and microscopic coronary artery disease, 2) increased myocardial interstitial connective tissue accumulation, and 3) left ventricular contractile dysfunction. ${ }^{19,22)}$ A lower ejection fraction in response to exercise concomitant with a normal resting ejection fraction has also been shown in other studies, and 
this finding suggests that the contractile reserve is decreased in symptomatic patients. ${ }^{23-24)}$ However, no patient revealed ischemic ST change or experienced chest pain during exercise testing in the present study as a cause of their reduced exercise capacity. Previous research ${ }^{25}$ has also shown that ejection fraction after myocardial infarction was lower in diabetic patients than in nondiabetic patients. However, our current data showed no difference between the DM and non-DM patients with regard to resting LVEF at 1 month after the onset of AMI, which suggests that cardiac function at rest is similar in DM and non-DM patients after AMI. ${ }^{10)}$ According to an earlier report in patients with type $2 \mathrm{DM}$, substantial correction in the metabolic control of diabetes has been found to be associated with a significant improvement in left ventricular systolic function at rest. ${ }^{26)}$ In another study that evaluated the effects of hyperglycemia on exercise performance, no association was found between hemoglobin Alc and exercise performance. ${ }^{27)}$ With regard to the relation between DM control and exercise capacity, there is no agreement. The debate is related to differences in the degree of glycemic control. We also reported previously that impaired exercise performance in DM patients was not associated with the degree of glycemic control when it is not severe. ${ }^{28)}$ Therefore, it seems likely that the blood glucose level is closely related to the reduced peak $\dot{\mathrm{VO}}_{2}$ and submaximal $\dot{\mathrm{VO}}_{2}$ in DM patients. Previously published findings support the observation that cardiac parasympathetic nervous activity may be related to the poor cardiac output response to exercise in patients with type $2 \mathrm{DM}$. Roy, et $a l^{8)}$ reported that poor cardiac response to exercise in diabetes patients resulted from a decrease in cardiac parasympathetic nervous activity and could be predicted by abnormal R-R variation. R-R variation data was not obtained in the present study. In another study ${ }^{28)}$ and in the present study, HR at rest tended to be higher in the DM group than in the non-DM group. The relation between cardiac parasympathetic nervous activity and exercise performance needs further study. Kremser, et al $^{19}$ ) have suggested that the abnormalities in exercise performance observed in type $1 \mathrm{DM}$ patients may be attributed to abnormalities of the cardiovascular autonomic nervous system. Diabetic neuropathy clearly affects the cardiovascular response to submaximal exercise, evidenced by an abnormal heart rate response. ${ }^{19)}$

Although there is ample evidence that resting sympathetic nervous activity is increased in patients with $\mathrm{CHF},{ }^{11)}$ there is relatively little information available regarding the relation between systemic sympathetic nervous activity and HR response during exercise in patients with DM complicated AMI. Collucci, et al ${ }^{12}$ ) reported that an another possibility for the attenuated chronotropic response to exercise is end-organ desensitization of the $\beta$-adrenergic pathway in the sinoatrial node. HR response during exercise at any given NE level was found to be low in CHF patients; more importantly, the increase in HR for any given increase in NE 
was markedly reduced. ${ }^{12)}$ In the present study, $\Delta \mathrm{HR} / \Delta \mathrm{NE}$ as an index for chronotropic response was significantly lower in our type 2 DM group than in our nonDM group. In addition, we found a significant positive correlation between $\Delta \mathrm{HR} /$ $\Delta \mathrm{NE}$ and $\mathrm{AT}$ and between $\Delta \mathrm{HR} / \Delta \mathrm{NE}$ and peak $\dot{\mathrm{V}} \mathrm{O}_{2}$. To the best of our knowledge, there are no publications describing the relation between $\Delta \mathrm{HR} / \Delta \mathrm{NE}$ and exercise tolerance. Our data are consistent with observations of an HR response relative to NE during exercise, and may support the hypothesis that the $\beta$-adrenergic pathway ${ }^{12)}$ contributes to attenuated chronotropic responsiveness in AMI patients with type $2 \mathrm{DM}$.

During the acute phase of AMI, various pathophysiological changes increase the contractility of the myocardium at the noninfarcted zone. ${ }^{29)}$ However, this response is impaired among diabetic patients and may be related to endothelial, microcirculation and diabetic cardiomyopathy, multivessel disease. ${ }^{29)}$ These responses might be responsible for decreased exercise capacity in patients with AMI complicated by type $2 \mathrm{DM}$.

Recently, Yu, et al ${ }^{30)}$ reported that diabetic patients with coronary heart disease without previous MI had a mortality nearly 5 times higher than that of nondiabetic patients with MI. For patients with coronary artery disease able to perform exercise until exhaustion, the all-cause and cardiovascular mortality decreased with increasing peak $\dot{\mathrm{V}}_{2} \cdot{ }^{31)}$ Endo, et al $^{32)}$ reported that chronotropic incompetence and the plasma catecholamine response to exercise are associated with a high risk of cardiac-cerebrovascular events in patients with type 2 diabetes. The influence of exercise training on the HR response relative to NE, or on the mortality in AMI patients with type 2 DM cannot be ascertained until further studies have been carried out. Exercise training for AMI patients with type 2 DM might improve not only exercise capacity, but also their health-related quality of life.

Conclusion: Patients with type 2 DM during recovery from AMI had impaired $\dot{\mathrm{V}} \mathrm{O}_{2}$ and cardiopulmonary responses to maximal and submaximal exercise tests compared with nondiabetic patients, even though cardiac function at rest was similar between the two groups. One mechanism of this impairment might be an impaired chronotropic response to exercise in AMI patients with type 2 DM.

Study limitations: The present study comprised a small sample and we examined changes in the HR response relative to sympathetic nervous activity during exercise. In the present study, indicators of parasympathetic nervous system activity such as the coefficient of variation of the R-R interval in the ECGs were not determined. Therefore, further studies are needed to investigate the interaction between the parasympathetic nervous system and HR response or exercise capacity in AMI patients with type $2 \mathrm{DM}$. 


\section{REFERENCES}

1. Aronson D, Rayfield EJ, Chesebro JH. Mechanisms determining course and outcome of diabetic patients who have had acute myocardial infarction. Ann Intern Med 1997; 126: 296-306.

2. Grossman E, Messerli FH. Diabetic and hypertensive heart disease. Ann Intern Med 1996; 125: 304-10.

3. Miettinen H, Lehto S, Salomaa V, et al. Impact of diabetes on mortality after the first myocardial infarction. The FINMONICA Myocardial Infarction Register Study Group. Diabetes Care 1998; 21: 69-75.

4. Ohmura T, Ueda K, Kiyohara Y, et al. Prevalence of type 2 (non-insulin-dependent) diabetes mellitus and impaired glucose tolerance in the Japanese general population: The Hisayama study. Diabetologia 1993; 36: 1198-203.

5. Fujishima M, Kiyohara Y, Kato I, et al. Diabetes and cardiovascular disease in a prospective population survey in Japan: The Hisayama Study. Diabetes 1996; 45: S14-6.

6. Fujishima M, Kiyohara Y, Ueda K, et al. Smoking as cardiovascular risk factor in low cholesterol population: The Hisayama Study. Clin Exp Hypertens A 1992; 14: 99-108.

7. Regensteiner JR, Sippel J, Mcfarling ET, et al. Effects of non-insulin dependent diabetes on oxygen consumption during treadmill exercise. Med Sci Sports Exerc 1995; 27: 875-81.

8. Roy TM, Peterson HR, Snider HL, et al. Autonomic influence on cardiovascular performance in diabetic subjects. Am J Med 1989; 87: 382-8.

9. Ewing DJ, Campbell IW, Clarke BF. Mortality in diabetic autonomic neuropathy. Lancet 1976; 1: 601-3.

10. Izawa $\mathrm{K}$, Tanabe $\mathrm{K}$, Ishiguro $\mathrm{T}$, et al. Cardiopulmonary response abnormalities during exercise in patients with non-insulin-dependent diabetes mellitus complicated acute myocardial infarction. Cardiovascular Reviews and Reports 2001; 22: 734-42.

11. Francis GS, Goldsmith SR, Ziesche S, et al. Relative attenuation of sympathetic drive during exercise in patients with congestive heart failure. J Am Coll Cardiol 1985; 5: 832-9.

12. Colucci WS, Ribeiro JP, Rocco MB, et al. Impaired chronotropic response to exercise in patients with congestive heart failure. Role of postsynaptic $\beta$-adrenergic desensitization. Circulation 1989; 80: 314-23.

13. UK prospective Diabetes Study (UKPDS) Group. Intensive blood-glucose control with sulphonylureas or insulin compared with conventional treatment and risk of complications in patients with type 2 diabetes (UKPDS 33). Lancet 1998; 352: 837-53.

14. The Diabetes Control and Complications Trial Research Group. The effect of intensive treatment of diabetes on the development and progression of long-term complications in insulin-dependent diabetes mellitus. New Engl J Med 1993; 329: 977-86.

15. Tanabe K, Yokoyama Y, Samejima H, et al. Effect of anaerobic threshold level exercise training upon oxygen uptake kinetics and sympathetic nervous activity in patients with chronic phase of myocardial infarction. $\mathrm{J}$ Noninvasive Cardiol 1998; 2: 31-7.

16. Hanson P. Clinical exercise testing. In: Resource Manual for Guidelines for Exercise Testing and Prescription. Philadelphia, Lea \& Febiger 1988; 205-22.

17. Beaver WL, Wasserman K, Whipp BJ. A new method for detecting anaerobic threshold by gas exchange. J Appl Physiol 1986; 60: 2020-7.

18. Wasserman K, Hansen JE, Sue DY, et al. Physiology of exercise. In: Principles of Exercise Testing and Interpretation. Philadelphia, Lea \& Febiger 1987; 3-26.

19. Kremser CB, Levitt NS, Borow KM, et al. Oxygen uptake kinetics during exercise in diabetic neuropathy. J Appl Physiol 1988; 65: 2665-71.

20. Ellestand MH. Chronotropic incompetence. The implications of heart rate response to exercise (Compensatory parasympathetic hyperactivity?) Circulation 1996; 93: 1485-7.

21. Wiens RD, Lafia P, Marder CM et al. Chronotropic incompetence in clinical exercise testing. Am J Cardiol 1984; 54: 74-8.

22. Gotzsche O. Myocardial cell dysfunction in diabetes mellitus. A review of clinical and experimental studies. Diabetes 1986; 35: 1158-62.

23. Mildenberger RR, Bar-Shlomo B, Druck MN, et al. Clinically unrecognized ventricular dysfunction in young diabetic patients. J Am Coll Cardiol 1984; 54: 234-8. 
24. Vered Z, Batter A, Segal P, et al. Exercise-induced left ventricular dysfunction in young men with asymptomatic diabetes mellitus (diabetic cardiomyopathy). Am J Cardiol 1984; 54: 633-7.

25. Orlander PR, Goff DC, Morrissey M, et al. The relation of diabetes to the severity of acute myocardial infarction and post-myocardial infarction survival in Mexican-Americans and non-Hispanic whites. The Corpus Christi Heart Project. Diabetes 1994; 43: 897-902.

26. Vanninen E, Mustonen J, Vainio P, et al. Left ventricular function and dimensions in newly diagnosed non-insulin-dependent diabetes mellitus. Am J Cardiol 1992; 70: 371-8.

27. Modan M, Meytes D, Rozeman P. Significance of high HbAlc levels in normal glucose tolerance. Diabetes Care 1988; 11: 422-8.

28. Izawa K, Tanabe K, Omiya K, et al. Cardiovascular response during exercise in patients with non-insulindependent diabetes mellitus-complicated acute myocardial infarction. J Jpn Phys Ther Assoc 2000; 27: 69-74.

29. Mak KH, Topol EJ, et al. Emerging in the management of acute myocardial infarction in patients with diabetes mellitus. J Am Coll Cardiol 2000; 35: 563-8.

30. Yu CM, Lau CP, Cheung BMY, et al. Clinical predictors of morbidity and mortality in patients with myocardial infarction or revascularization who underwent cardiac rehabilitation, and importance of diabetes mellitus and exercise capacity. Am J Cardiol 2000; 85: 344-9.

31. Vanhees L, Fagard R, Thijs L, et al. Prognostic significance of peak exercise capacity in patients with coronary artery disease. J Am Coll Cardiol 1994; 23: 358-63.

32. Endo A, Kinugawa T, Ogino K, et al. Cardiac and plasma catecholamine responses to exercise in patients with type 2 diabetes: prognostic implications for cardiac-cerebrovascular events. Am J Med Sci 2000; 320: 24-30. 